\title{
HACIA LA PROFESIONALIZACIÓN DE LA FUNCIÓN DIRECTIVA EN LATINOAMÉRICA
}

\author{
Rafael Martínez Puón \\ Universidad Nacional Autónoma de México, México \\ rafael.martinez@ife.org.mx
}

\begin{abstract}
RESUMEN
El artículo tiene el propósito de abordar una de las tendencias en materia de gestión de las personas de los últimos tiempos, y que tiene que ver con la profesionalización de la función directiva. Si bien el tema en algunos países de economías y democracias consolidadas ha representado su institucionalización, en países de la región latinoamericana, salvo el caso chileno y alguno más, continúa inerte. Por mismo, la intención de este documento es aportar ideas, conceptos, sobre lo que es y representa la función directiva y su profesionalización, pero principalmente exponer posibles componentes que puedan resultar de utilidad para el establecimiento de un sistema profesional para países de América Latina.
\end{abstract}

Palabras clave: Directivos públicos, Servicio civil, Profesionalización, América Latina. 


\title{
TOWARDS THE PROFESSIONALIZATION OF THE DIRECTIVE FUNCTION IN LATIN AMERICA
}

\begin{abstract}
This article aims to address one of the latest tendencies in the field of human resource management, and is related to the professionalization of the directive function. Although in some countries with consolidated economies and democracies this issue has implied an institutionalization, in Latin American countries - except for Chile and a few others- it remains inactive. For this reason, the purpose of this document is to provide ideas and concepts on what the directive function and its professionalization is and represents, but mainly to illustrate possible components which may prove useful for the establishment of a professional system for Latin American countries.
\end{abstract}

Keywords: Public managers, Civil service, Professionalization, Latin America. 


\section{INTRODUCCIÓN}

En el marco de las tendencias de la profesionalización de la función pública a nivel mundial, uno de los temas relevantes o destacados es el vinculado con el diseño de un sistema de profesionalización o carrera para altos directivos públicos o directivos públicos ${ }^{\mathrm{I}}$, o también llamada función directiva profesional a través de sistemas de profesionalización denominados servicios civiles senior ${ }^{2}$ (SCS). Todo ello, en el marco de administraciones públicas

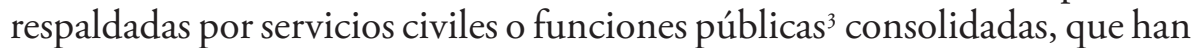
visto como una franja especial de sus funcionarios, llámese esos directivos a los que se alude, requieren de capacidades o competencias específicas y por lo tanto de un tratamiento especial, de modo que dicho objeto de estudio se convierta en elemento fundamental para el fortalecimiento de sus organizaciones cuyo éxito descanse precisamente en la calidad de su dirección (Brosnahan 2000). Es más, nos atrevemos a decir, que hoy día éste es un asunto que necesariamente debe formar parte de la agenda de toda administración pública que se precie o aspire a ser moderna.

Un dato relevante en cuanto a los países que forman parte de la Organización para la Cooperación y el Desarrollo Económico (OCDE), es el que nos aporta Manuel Villoria y Eloisa del Pino en su libro Dirección y Gestión de Recursos Humanos en las Administraciones Públicas (2009), basándose en un informe de este organismo, denominado The State of Public Service (2008), cuando señalan que:

Casi todos los países de la OCDE tienen un sistema de directivos profesionalizado, los que quedan por debajo de la media son Turquía, Japón, República Eslovaca, Islandia e Italia (a pesar de todos los intentos), Alemania, Irlanda, y en último lugar de ese índice de institucionalización está España.

I Se anticipa que a largo del texto se estarán utilizando de manera indistinta tanto los términos de función directiva, alta burocracia, alta función directiva o servicios civiles senior. En el caso de términos indistintos para personas estarán los siguientes: directivos públicos, altos directivos públicos, gerentes públicos, managers senior, servidores civiles senior o servidores públicos senior, oficiales senior, oficiales ejecutivos senior, altos funcionarios o incluso en el capítulo tres aparece el término de burócratas también como figura homóloga.

2 Senior denota el más alto rango en virtud de la antigüedad en el servicio. El término no se utiliza en países como España o Francia, en los que se prefiere usar el equivalente a alto funcionario, alta función pública o haut function publique (respectivamente) o en países como Alemania o Austria que se usa el equivalente "cúspide/cima de los servidores civiles" (Spitzanbeamte).

3 Entiéndase por servicio civil o función pública como aquél sistema de empleo en que las personas ingresan a la administración pública a través de sus propios méritos y en igualdad de oportunidades (OCDE 2008: I6). 
Agregaríamos a este comentario y por encima de este supuesto último lugar, el caso de México, que ni siquiera cuenta con una ley o norma en la materia, aunque con intentos escasos, derivados de la publicación de la Ley del Servicio Profesional de Carrera para la Administración Pública Federal en el año 2003.

En efecto, tal como lo menciona Ferrel Heady (1996), en décadas recientes a la función directiva se les ha proveído, ante un escenario de países con estabilidad política y una burocracia desarrollada, de herramientas e insumos de carácter político y administrativo, que los ha llevado a que se les denominen como The Western Mandarians, no como sustitutos del personal administrativo perteneciente al servicio civil, ni de los políticos, sino como una franja de personal que se posiciona entre ambos. Esencialmente, como hacedores de políticas y que a la vez tratan de conciliar a los dos esferas de personal antes mencionadas. O para ser más precisos en cuanto a la definición de estos servicios llamados senior o SCS: "verticalmente es una institución mediadora entre los políticos designados y los miembros del servicio civil, y horizontalmente es un mediador entre los diferentes ministerios o departamentos o agencias" (OCDE 2008). Adicionalmente, sobre la función directiva se han pronunciado algunos organismos internacionales como la propia OCDE (1995, 1997, I999, 2000, 2008), el Banco Mundial (BM 2003), el Banco Interamericano de Desarrollo (BID 2003), el Centro Latinoamericano de Administración para el Desarrollo (CLAD 2003), que han señalado la necesidad de fortalecer la capacidad directiva de las organizaciones, ya sea a través de estos sistemas especiales o esquemas similares. En cuanto a fundamentos teóricos, la idea de mejorar la capacidad directiva de las organizaciones y de formar directivos públicos tiene su respaldo, principalmente por los postulados de la Nueva Gestión Pública ${ }^{4}$, cuya pretensión ha sido el

4 Sobre este tema hay una amplia literatura. Algunos apuntes señalan a la Nueva Gestión Pública, como una propuesta emergente de los años setenta y ochenta, y con sólidas raíces de la teoría de la organización y de la economía política, la cual surge como respuesta a los problemas que presenta la Administración Pública Tradicional. La Nueva Gestión Pública de acuerdo con la definición del Comité de Gestión Pública de la OCDE, representa "un nuevo paradigma de la gestión pública... dirigido a fomentar una cultura orientada a la actuación de un sector público menos centralizado" (citado por Mathiasen 1998). En su base la Nueva Gestión Pública va dirigida a mejorar la actuación de su gobierno y sus gerentes. La Nueva Gestión Pública implica poner un especial énfasis en la gestión por encima de las políticas; en organizar el gobierno en grupos de agencias y de departamentos, más que en pirámides tradicionales y jerarquizadas; en la adopción de toma de decisiones estratégicas y orientadas a la obtención de resultados y medidas de mejora de la calidad; en recortar los gastos en vez de crear nuevos; en una mayor flexibilidad; en una mejora de la eficiencia en la prestación de servicios públicos; en la promoción de la competencia en el ámbito y entre organizaciones del sector público (Keraudren y Mierlo I998: $4 \mathrm{I}-42)$. 
replanteamiento del quehacer administrativo tradicional y proponer, entre otras cosas, precisamente a los directivos públicos como factor de cambio, a partir de entender que no hay capacidad directiva o gerencial, donde la actividad es, en lo fundamental, la mera aplicación impersonal de reglas y la observancia fiel de procedimientos establecidos (Longo 2006:70). De modo que la atribución jerárquica no equivale a la habilitación real para el ejercicio de una función directiva (Brosnahan 2000). En ese sentido, se habla de un "derecho de gestionar" de los servidores públicos como precedente constitutivo de la dirección pública.

Es conveniente señalar que el tema de la función directiva profesional no se agota exclusivamente en el diseńo de leyes, como bien pudiera ser una solución o propuesta inmediata para países como los latinoamericanos, en los que prevalece una cultura preponderantemente legalista. Este asunto también tiene que ver con identificar y fortalecer capacidades o competencias directivas y en crear los entornos propicios para que las personas sean capaces de dirigir de mejor manera a sus organizaciones, en mejorar sus desempeños y disminuir sus niveles de improvisación y corrupción. Los resultados nos parecen que están a la vista con los países que se han enlistado al inicio de la exposición que cuentan con sistemas de profesionalización para sus directivos públicos.

Sin embargo, la gran pregunta que surge es ¿qué acontece en Latinoamérica con relación a este tema? Salvo el caso chileno que es de lo más destacado, y una que otra legislación de algún otro país (Colombia, República Dominicana, Brasil) que enuncian el tema, la realidad es que hablar de una función directiva profesional es un bien escaso. Si ya de por sí, el asunto de la profesionalización de las administraciones públicas latinoamericanas, no nos señala indicios de su consolidación en la mayoría de los países, el asunto de la función directiva profesional es todavía más lejano.

De hecho, se está consciente de que un posible punto de debate que irrumpe inmediatamente, y éste sería en parte el planteamiento del problema, giraría en torno a preguntar: ¿Por qué crear un sistema de profesionalización directivos públicos si no se ha podido consolidar un servicio civil? Lo que nos situaría en el terreno del $\mathrm{ABC}$ obligado. Al respecto, es importante seńalar, que se considera que no necesariamente se tendría que aplicar tal fórmula; incluso se puede partir de dos supuestos a considerar: poder hacerlo de manera simultánea o que lo segundo reimpulse al primero.

No obstante, se considera que sobre esta asignatura habría que trabajar en los próximos años, de ahí de establecer algunos de los posibles componentes 
como bases para un sistema profesional en la función directiva; objetivo principal de este artículo.

\section{APROXIMACIONES CONCEPTUALES Y TEÓRICAS A LA FUNCIÓN DIRECTIVA}

Hablar de función directiva o dirección pública, nos obliga a tomar como referencia algunos estudios, entre los más importantes, realizados a lo largo del siglo XX que van desde las escuelas clásicas de la función directiva como los de Henri Fayol, i9r6 (I96I), Harry Hopt, I933 (I96r), Paul Holden I94I (I968), Luther Gulick, 1936 (I987), así como Harwood Merrill y Elizabeth Marting, I952 (I958), que principalmente vinculan el tema de la función directiva con el ciclo de gestión. Conceptos más, conceptos menos, encontramos como elementos comunes a la previsión, planificación, programación, organización, dirección, coordinación, motivación, información, control etc. Por supuesto, que el tema de ninguna manera se agota ahí. Por el contrario, éste presenta una serie de hallazgos que van más allá de las funciones de gestión, y tiene que ver con capacidades, habilidades, componentes afectivos, aspectos informales, relaciones interpersonales, tiempo destinado al trabajo de oficina y fuera de ella, entre otros. El interés se centra en saber ¿quiénes son y qué realmente hacen los directivos públicos? ¿En dónde los ubicamos? Entre otras cosas.

Con relación a los elementos mencionados, se indica que son pocos los estudios que han intentado ir más allá de lo estrictamente vinculado con la gestión. Al respecto, al igual que en el primer párrafo, se tiene que hacer alusión a estudios que ya resultan ser clásicos, como los de Stewart (I988), Likert (I961), Sayles (I964), Kotter (1983), y principalmente los de Mintzberg (1983, I996, 2000, 2005), cuyo desarrollo no sólo ha sido en el ámbito privado sino también en el público, así como los trabajos de Laufer y Burluad (I989), o estudios muy particulares en algunas funciones públicas como los Price Waterhouse Coopers (I998) o de la propia OCDE (1999). En el ámbito latinoamericano destaca el trabajo de Kliksberg (I983).

De tal manera, siendo probable que con la combinación de ambas visiones llámese la de gestión con la de elementos adicionales, hoy día existan definiciones como las siguientes:

La dirección no es un simple componente de la gestión, tiene que ver con múltiples talentos, entre los que deben figurar la integridad, la intuición, la capacidad de inspirar a los demás, una profunda conciencia de sí, el valor de innovar y un discernimiento rápido e infalible. La dirección supone un espíritu inquebrantable, un espíritu visionario, y un real afecto por las personas a las que se dirige (Brosnahan 2000). 
"La dirección como la movilización de personas para hacer frente a realidades problemáticas, afrontarlas y resolverlas" (Heifetz 1994) o "La dirección como el proceso de persuasión o el ejemplo por el que el individuo (o un equipo) conduce a un grupo a perseguir objetivos defendidos por los directivos o compartidos por el directivo y sus seguidores" (Gardner I 990). Como se puede observar, el tema nos abre una serie de posibilidades de cómo entender y abordar un asunto de esta naturaleza.

\section{¿EN DÓNDE UBICAMOS A LOS DIRECTIVOS PÚbliCOS DESDE EL PUNTO DE VISTA ORGANIZACIONAL?}

Para ello, cabe hacer algunas consideraciones previas vinculadas sobre todo a aspectos de carácter organizacional. Primero, se tiene que señalar que en toda organización burocrática los temas relacionados con la división del trabajo, la jerarquía funcional dividida en puestos que desempeñan diversos roles, procedimientos de trabajo, la comunicación por escrito, así como el nivel de especialización de las personas integrantes con una retribución adecuada, se presentan como elementos operando un todo "aparentemente" armonizado que de forma racional a través de rutinas, procesos y cumplimiento de normas, alcanzan los diferentes objetivos de la organización (Weber 1979). Todo en el marco de una suerte de plantilla o modelo descriptivo que responde a la "lógica de lo adecuado" (Peters 2003).

Palabras más, palabras menos, es el esquema formal en el que se han inspirado la mayoría de las burocracias o administraciones públicas occidentales 5 . Para ello, uno de los temas principales, es cómo se distribuyen los puestos de acuerdo con la jerarquía funcional y cuál es el nivel o porcentaje que le tendría que corresponder a las distintas esferas de personal. Sobre este punto, se coincide con lo que señala Guy Peters (I 995: 90) que señala lo siguiente:

La controversia de la designación política o de la designación por méritos - por mencionar los ejemplos centrales- es cuestión de grado. Virtualmente todos los sistemas políticos tienen cierto nivel en que las

$5 \mathrm{Al}$ respecto, cabe señalar que la moderna aparición de una organización burocrática no obedece al azar; sino que es el resultado de presupuestos económicos y sociales muy concretos, que sólo han surgido en un momento histórico determinado: desarrollo de una economía monetaria, desarrollo cuantitativo de determinadas bases sociales, especialmente el Estado y de los partidos de masas, desarrollo cualitativo de las actividades administrativas, superioridad técnica sobre cualquier otra forma de organización (puesto que es más barata, más rápida, más objetiva y de resultados previsibles), concentración de los instrumentos materiales en manos de las dominus y nivelación de las diferencias económicas y sociales de los dominados (Weber I 979: 709) . 
designaciones son claramente políticas - con frecuencia posiciones de "elaboración de políticas"- y también tienen empleos que se ocupan en forma relativamente rutinaria por alguna especie de sistema de méritos. Por tanto, el problema consiste en saber hasta qué nivel de la escala de la jerarquía administrativa podrán hacerse designaciones por méritos o por lo menos no abiertamente políticas, o hasta dónde llegan los límites de las designaciones políticas. En esto consiste el meollo de la cuestión.

No obstante este argumento, si se tuviera que recurrir a un esquema simple, en el que se mostrara la forma en que está organizada una estructura burocrática, éste sería el siguiente.

\section{Gráfico I: Estructura burocrática tradicional}

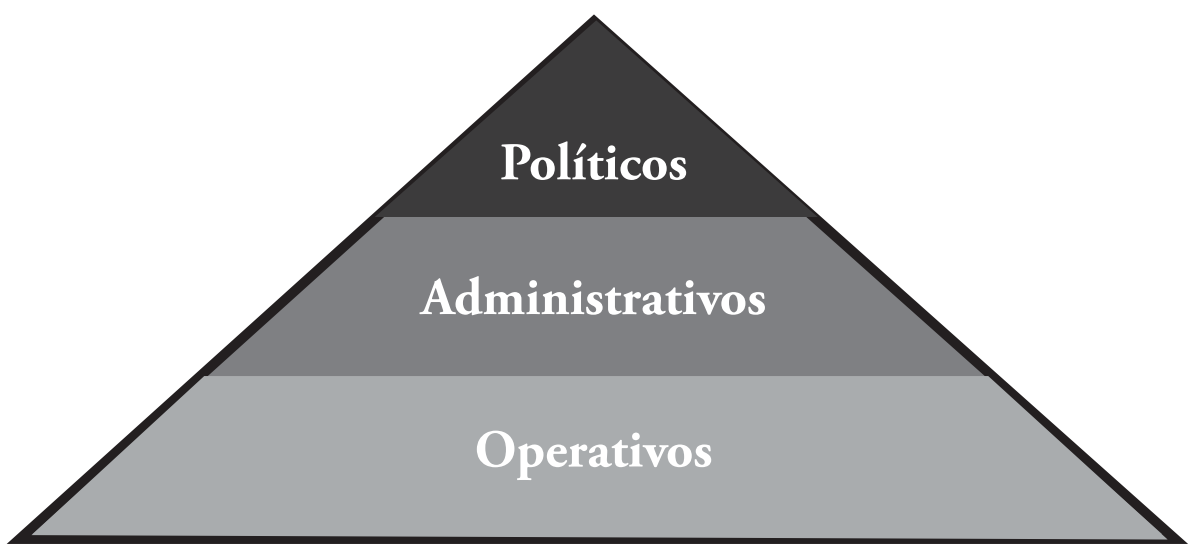

Fuente: Elaboración propia.

Sin embargo, se sabe que bajo este esquema tradicional suele haber entre cada una de estas divisiones una clasificación mucho más sofisticada de puestos, que pueden ser sumamente diversos e incluso únicos con base en las características particulares de algunas estructuras burocráticas. Por lo que aunado a las categorías de personal mencionadas en la pirámide, se tienen que sumar a esta plantilla otros tipos de personal, llámese personal que desempeña funciones de asesoría, gente contratada por servicios profesionales, etc. (Dussauge 2008).

El riesgo de seguir utilizando este esquema simple, pero de acuerdo también con lo que acontece en la mayoría de las burocracias que lo usan, es que los puestos políticos suelen ser cubiertos a través de la designación política $^{6}$; para el caso de los puestos administrativos (en el supuesto de

6 Por mencionar un ejemplo, para el caso de nombramientos o designaciones políticas, es interesante ver el caso de los Estados Unidos, en el que se establecen una serie 
existir un servicio civil), se suelen cubrir por concurso o un sistema de mérito. Y en la parte baja de la pirámide llámese operativos, suelen existir diversos mecanismos, desde que estos puestos formen parte de sindicatos, hasta que su cobertura sea por designación o mérito.

Hay que señalar que este esquema en comento, ha sido objeto de muchos análisis y cuestionamientos, que van desde la coordinación existente entre estas esferas de personal, de su nivel de comunicación, y de los roles que les corresponde desarrollar a cada una de las personas que ocupan puestos, hasta de su nivel de contribución para alcanzar los diferentes objetivos y metas de la organización.

Por ejemplo, en cuanto a roles desempeñados, de acuerdo con Longo (2002), en primer término están los políticos que son las personas que asumen y ejercen responsabilidades de gobierno en las instituciones administrativas públicas. En segundo término, están los administrativos que forman parte de esa línea media que responde ante los políticos del funcionamiento de parcelas concretas de la actuación administrativa. Esta franja representa un espectro heterogéneo en el que pueden confluir distintas categorías de funcionarios o servidores públicos. Por último, está el personal operativo o llamado por algunos autores, como Lipsky (I 980), como street-level-bureaucracy, que en su mayoría es personal de atención a ventanilla y que preponderantemente está representado por los sindicatos, que asumen tareas de representación y de defensa de intereses de personal, en la esfera laboral. Cada uno de estos actores, independientemente de su descripción arquetípica, suelen responder a lógicas de interés distintas y la actuación varía de acuerdo con los diferentes contextos existentes. De modo que es posible que en algunos casos exista mayor proclividad hacia la cooperación entre actores y en otros no.

de reglas del juego que delimitan muy bien las fronteras para con los otros tipos de personal y no haya una interferencia. Primero, la proporción de nombramientos políticos de los servidores civiles es muy reducida y ellos normalmente no se integran al servicio civil de carrera cuando su mandato termina. Segundo, es transparente y claro para ambos partidos políticos que después de cada cambio, los nombramientos políticos pueden removerse. Tercero, el Congreso está encargado de reunir toda la lista de posibles nombramientos para todo el mandato presidencial (el llamado Libro Ciruela). Cuatro, muchos nombramientos políticos se han ratificado por el Senado. En este proceso, los Presidentes tratan de nombrar gente con credenciales relevantes. Como explicó la Casa Blanca en una entrevista oficial, los nombramientos políticos se filtran y clasifican antes de enviarse al Presidente para el nombramiento. En consecuencia, los méritos de los candidatos terminan considerándose muy serios, aunque no hay una competencia formal. Finalmente, los nombramientos políticos no interfieren con el proceso de nombramiento de los servidores civiles senior, quienes son nombrados a través de un sistema de mérito o un proceso competitivo (OCDE 2008). 
Pero sin duda, el debate más frecuentado tiene que ver con la clásica dicotomía política-administración (Weber I979, Wilson I887, Goodnow I900, Suleiman 1984) ¿Qué sucede cuando ambas partes no se encuentran en un diálogo adecuado? ¿Cómo afecta esta disfuncionalidad en el funcionamiento del sistema burocrático? ¿Cómo encontrar un balance adecuado entre ambas partes? ¿Políticos versus administrativos profesionales? ¿Política versus administración pública? ¿Qué sucede cuando la esfera de los políticos es preponderante sobre la esfera administrativa profesional o al revés?7

Cabe señalar que estas supuestas disfunciones fueron en su momento detectadas entre los múltiples diagnósticos al modelo tradicional de administración weberiano, como señales de agotamiento y con propuestas de avanzar hacia un campo de posibles alternativas de cambio. Entre las múltiples alternativas de solución a esta dicotomía política-administración, está la de crear un vaso comunicante o "bisagra" entre la política y la administración que recae precisamente en la función directiva o en el rol de los directivos públicos, al otorgarles el ejercicio de funciones polivalentes a lo largo de toda la administración; en el interés de que en su calidad de negociadores y coordinadores con otros actores distintos a los de la estructura burocrática y a nivel interministerial, puedan mantener un permanente dinamismo en el funcionar de las administraciones. Por supuesto, en ellos recaería el darle respuesta a muchos de los problemas político-administrativos precisamente en su calidad de enlaces, que un solo poder o ministerio no resolvería. Por lo que de los directivos públicos se demandaría un enorme liderazgo estratégico (esto es, hacer que las cosas sucedan) para darle solución a diversos problemas y a las demandas de los ciudadanos, de ahí que su papel se convierta en fundamental en el proceso de transformación de las administraciones públicas.

De modo que, si regresamos al esquema burocrático con el que hemos venido trabajando en este artículo, tendríamos que insertar o resaltar a la categoría de los directivos públicos de la forma siguiente.

Sobre estas últimas preguntas, también desde hace muchos años se ha registrado un debate diverso e interminable y con múltiples visiones que va desde buscar el balance adecuado, advertir los riesgos de tener burocracias desbocadas o como rehenes de los sistemas de partidos hasta de clasificar a las burocracias con base en su vínculo con las características de los sistemas políticos. Véanse los trabajos de Jacoby (I973), Rowat (I988), Peters (I995), LaPalombara (I963), Riggs (I970) y Morstein, Fritz (1957). 


\section{Gráfico 2: Estructura burocrática que incluye a los directivos o altos directivos públicos}

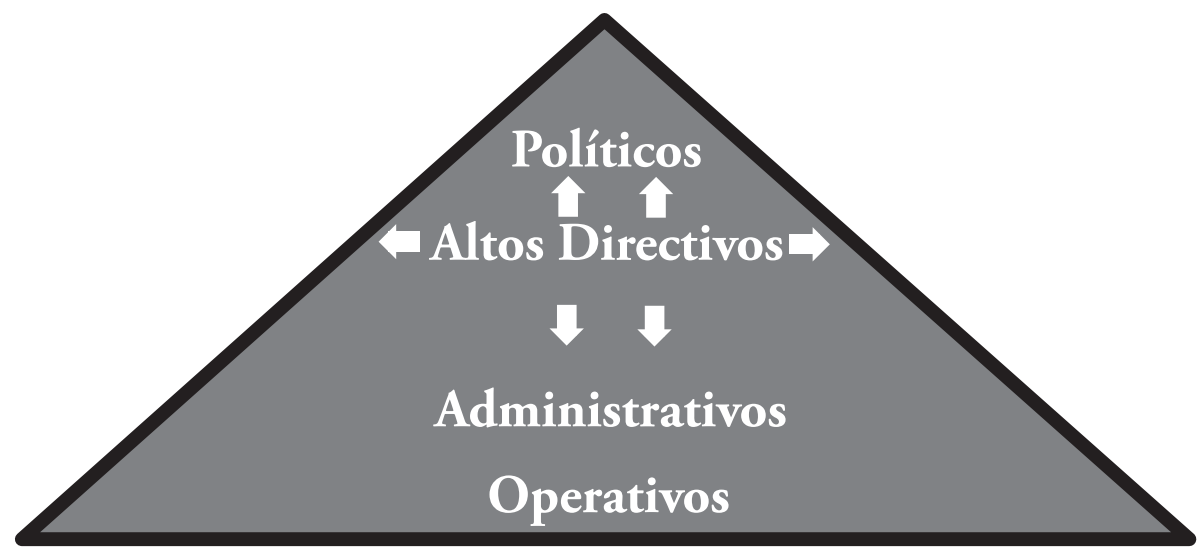

Fuente: Elaboración propia

En el mismo orden de ideas con respecto a la regulación de la función directiva, el Informe de la Comisión 2005 del Estatuto Básico del Empleado Público español (2005: 64), considera que la regulación de esta figura, ha asumido connotaciones muy distintas en unos u otros países, conforme a sus tradiciones y a su evolución. En casi todos ellos ha tropezado con dificultades, ya que supone no sólo introducir un modelo de gestión pública que contrasta con usos burocráticos muy asentados, sino también crear un nuevo grupo profesional que se inserta en la dirección política y la función pública superior de carrera, precisamente en ese espacio difuso y nunca bien delimitado en que se separan y confluyen, al mismo tiempo, la política y la administración.

Es en este argumento que se centra parte de la atención destinada a la función directiva como un objeto particular de estudio, que se ha venido materializando de diversas maneras, que van desde la creación de una normatividad específica, procesos de selección diferenciados, así como de formación. Se sostiene que esta corriente surge de la necesidad, en cuanto a que los sistemas tradicionales de servicio civil han manifestado su incapacidad para producir perfiles directivos en la proporción requerida y para estimular la práctica gerencial debidamente. Por ello, la profesionalización de los directivos públicos se ha convertido en una prioridad para los reformadores, y ha exigido concentrar políticas específicas de gestión de recursos humanos en la franja superior de los sistemas de servicio civil (Longo 2004:203).

Dicha selección de puestos ha demandado la instrumentación de reglas básicas específicas que al final han llevado a una plena diferenciación de la 
carrera confinada al servicio civil. Ciertamente, la tendencia ha consistido en diferenciar la carrera de directivos públicos a la del servicio civil como se puede ver a continuación en la siguiente tabla:

\section{Tabla I: Función Directiva. ¿¿Está diferenciada?}

$\begin{array}{cc}\text { País } & \text { Sí/No } \\ \text { Alemania } & \text { No } \\ \text { Austria } & \text { No } \\ \text { Bélgica } & \text { Sí } \\ \text { Canadá } & \text { Sí } \\ \text { Espańa } & \text { No } \\ \text { Estados Unidos } & \text { Sí } \\ \text { Francia } & \text { No } \\ \text { México } & \text { No } \\ \text { Holanda } & \text { Sí } \\ \text { Italia } & \text { Sí } \\ \text { Japón } & \text { No } \\ \text { Reino Unido } & \text { Sí } \\ \text { Suecia } & \text { Sí } \\ \text { Chile } & \text { Sí } \\ \text { Colombia } & \text { No } \\ \text { Nueva Zelanda } & \text { Sí }\end{array}$

Fuente: Longo (2003), con agregados propios de otros paises.

Esto también conlleva a una cierta definición o término propio de este segmento de personal como se puede observar en la siguiente tabla: 


\section{Tabla 2: Definición propia de servidores civiles senior (muestra de los países de la OCDE)}

\begin{tabular}{|c|c|c|c|c|}
\hline País & Término & Definición central & $\begin{array}{l}\text { ¿Define } \\
\text { el SCS? }\end{array}$ & $\begin{array}{c}\text { Fecha de crea- } \\
\text { ción }\end{array}$ \\
\hline Alemania & $\begin{array}{l}\text { Alto Servidor Civil } \\
\text { (Spitzenbeamte- la } \\
\text { cima del servidor) }\end{array}$ & $\begin{array}{l}\text { Niveles organizaciona- } \\
\text { les/ Grupos salariales }\end{array}$ & No & - \\
\hline Australia & $\begin{array}{l}\text { Servicio Ejecutivo } \\
\text { Senior }\end{array}$ & $\begin{array}{l}\text { Grupo salarial/ Nive- } \\
\text { les organizacionales }\end{array}$ & Sí & 1984 \\
\hline Bélgica & $\begin{array}{c}\text { Altos Funcionarios } \\
\text { (Haut fonction- } \\
\text { naires) }\end{array}$ & $\begin{array}{c}\text { Niveles organizacio- } \\
\text { nales }\end{array}$ & Sí & 2000 \\
\hline Canadá & Grupo ejecutivo & Escalas & Sí & - \\
\hline España & $\begin{array}{l}\text { Alta Función } \\
\text { Pública }\end{array}$ & $\begin{array}{c}\text { Niveles organizacio- } \\
\text { nales }\end{array}$ & No & - \\
\hline $\begin{array}{l}\text { Estados } \\
\text { Unidos }\end{array}$ & $\begin{array}{l}\text { Servicio Ejecutivo } \\
\text { Senior }\end{array}$ & Grupo salarial & Sí & 1979 \\
\hline Francia & $\begin{array}{c}\text { 1) Cuadros } \\
\text { ejecutivos (Cadres } \\
\text { dirigeants)/ Altos } \\
\text { cuadros (Cadres } \\
\text { superieurs) } \\
\text { 2) Altos Fun- } \\
\text { cionarios (Haut } \\
\text { fonctionnaires) }\end{array}$ & $\begin{array}{l}\text { Niveles organizacio- } \\
\text { nales y selección de } \\
\text { miembros corpora- } \\
\text { tivos }\end{array}$ & No & - \\
\hline Italia & $\begin{array}{l}\text { Dirigenza }\left(1^{\circ} \text {. y } 2^{\circ} \text {. }\right. \\
\text { nivel ejecutivo- pri- } \\
\text { ma y seconda fascia })\end{array}$ & $\begin{array}{c}\text { Niveles organizacio- } \\
\text { nales }\end{array}$ & Sí & 1998 \\
\hline Países Bajos & $\begin{array}{l}\text { Servicio Civil } \\
\text { Senior(Algemene } \\
\text { Bestuursdienst) }\end{array}$ & $\begin{array}{l}\text { Escalas del servicio } \\
\text { civil/ Niveles organi- } \\
\text { zacionales }\end{array}$ & Sí & 1995 \\
\hline $\begin{array}{l}\text { Nueva } \\
\text { Zelanda }\end{array}$ & $\begin{array}{l}\text { Servicio Ejecutivo } \\
\text { Senior }\end{array}$ & $\begin{array}{c}\text { Niveles organizacio- } \\
\text { nales }\end{array}$ & Sí & 1991 \\
\hline $\begin{array}{l}\text { Reino } \\
\text { Unido }\end{array}$ & $\begin{array}{l}\text { Servicio Civil } \\
\text { Senior }\end{array}$ & Grupo salarial & Sí & 1996 \\
\hline
\end{tabular}

Fuente: OCDE (2008).

Con referencia al tamaño de esta estructura, el número puede variar según la magnitud de los servicios civiles existentes, pero según estudios de la misma OCDE (I999:I9) el porcentaje no va más allá del $2 \%$ con relación al personal que forma parte del servicio civil. Sobre esta cantidad 
enfatizar que los servicios civiles senior varían según el país, en términos de diversidad y tamaño. Los países más pequeños tienen menos de I.000 servidores civiles senior (Bélgica, Nueva Zelanda y los Países Bajos), mientras que los más grandes tienen más de 2.000 (Australia, Canadá, Francia, Italia, y el Reino Unido). Y están las grandes excepciones como los Estados Unidos que cuenta con alrededor de 7.000 funcionarios de esta naturaleza (OCDE 2008: 7). Lo mismo acontece con los niveles o límites hasta los cuales llega la carrera de directivos públicos, y que marcaría las fronteras entre estos y los políticos. Esto por supuesto que también varía de país a país ${ }^{8}$.

Ahora bien, si se tuviera que definir una carrera para directivos públicos, según la OCDE (I999: 9), se diría que es una estructura y un sistema reconocido de gestión para altas posiciones no políticas (llámese para funciones de directivos públicos) en el gobierno. Es un sistema de servicio civil que entrena y forma directivos para el desempeño de funciones ad-hoc. Es un servicio que principalmente es gestionado a través de instituciones y procesos apropiados para proveer estabilidad y profesionalismo a este grupo de altos directivos, pero con la necesaria flexibilidad en la composición de los gobiernos.

De esta definición se tienen que destacar los siguientes elementos (OCDE 2008):

I. Las posiciones más altas en el gobierno. Los puestos ocupados por el servicio civil senior son los más altos en jerarquía (en departamentos centrales y agencias). Normalmente, se sitúan justo debajo de los nombramientos políticos que se dan mediante procedimientos no competitivos. El número de niveles que comprende el servicio civil senior depende de la definición usada por cada país. Los puestos más altos del gobierno pueden definirse por medio de un rango específico de posiciones (secretarías generales o directores generales), estableciendo un grado o escala personal que sean atribuibles a la persona y al puesto o mediante un grupo salarial.

2. Nombramientos competitivos. El nombramiento abierto significa que hay una adecuada convocatoria para candidatos internos y externos, y basado en el mérito, las capacidades, experiencia, desempeño de los

8 Sobre este punto, se recomienda ampliamente el estudio de Matheson, Alex, Boris Weber, Nick Manning and Emmanuelle Arnould (2007: 16). En este estudio en el que se expone la situación de doce países como Bélgica, Dinamarca, Corea, Italia, México, Nueva Zelanda, Polonia, Reino Unido, Suecia, Francia, Estados Unidos y Sudafrica, se explican los niveles hasta los que llega la carrera de directivos públicos o lo sistemas senior. 
candidatos.

3. Instituciones y procesos adecuados de gestión de recursos humanos. Nombramiento, remociones, promociones, evaluación del desempeño, salarios y demás, se determinan por procesos en los que se introducen mecanismos de "equilibrio de poder". Este equilibrio es necesario para asegurar la competencia abierta y evitar la interferencia política. En algunos casos, hay una comisión que hace los nombramientos dentro del departamento, la cual evalúa y clasifica a los candidatos. Este trabajo puede ser verificado por un cuerpo independiente, o el propio cuerpo independiente puede organizar todo el proceso de nombramiento o parte de él. En estos ejemplos, las instituciones y los procedimientos otorgan una competencia real al reclutamiento. En otros países, el candidato es seleccionado sólo por una vacante superior. En estos casos, los criterios de competencia a menudo se anulan en la práctica, por ejemplo, simulan la descripción del perfil del puesto para anunciarlo en la gaceta oficial para potencial preselección del candidato, incluso publican antes la vacante. No existe una definición universal de instituciones y procesos adecuados de gestión de recursos humanos, ya que las instituciones tienen contextos específicos.

4. Funciones. Los servidores civiles senior pueden desempeñar una o varias funciones esenciales: I) asesoría política, analizando e informando sobre contenidos políticos a ministros, normalmente sin incluir la opinión de partidos políticos, que podría ser el trabajo de los asesores o nombramientos políticos, 2) eficacia operativa, administrando recursos para alcanzar los resultados esperados de los programas y servicios, 3) eficacia en servicios corporativos, gestión de recursos financieros, personal, tecnología e infraestructura.

5. Separación formal de un grupo definido. La separación significa que el personal perteneciente al servicio civil senior, tiene diferentes reglas y planes del resto del servicio civil. Aquellos planes diferentes podrían ser: estructura salarial, contratación, nombramiento, acuerdos de desempeño y evaluación, sistema de equilibrio de poderes, etc.

6. Flexibilidad respetando los procesos. La flexibilidad quizá necesite homogeneizar los procesos competitivos en el nombramiento, para la correcta relación entre servidores civiles senior y el ministro (o nombramientos políticos). Podría acompañarse de procesos adecuados, cuando por ejemplo, los ministros tienen la oportunidad de aceptar o rechazar un nombramiento de una comisión autónoma, o acceden a evaluación independiente cuando hay un desempeño poco confiable o inadecuado, pueden destituir a un servidor civil senior. En estos casos, 
deberían de respetarse los procesos para evitar la arbitrariedad de los políticos.

7. Dirección centralizada. Los servicios civiles senior deben estar centralizados o monitoreados para prevenir la interferencia política que se da en el nivel ministerial individual, especialmente en promoción, descenso y salarios basados en el desempeño.

En la misma línea de pensamiento, la Carta Iberoamericana de la Función Pública (2004) señala:

...los directivos públicos corresponden aquel segmento de cargos o dirección inmediatamente subordinado al nivel político de los gobiernos, cuya función es dirigir, bajo la orientación estratégica y el control de aquél, las estructuras y procesos mediante los cuales se implementan las políticas públicas y se producen y proveen los servicios públicos. Se trata de una función diferenciada tanto de la política como de los profesionales de las políticas públicas que integran la función pública ordinaria. La adecuada definición y consolidación de una dirección pública profesional son básicas para un correcto diseño institucional de los sistemas públicos contemporáneos.

No obstante los avances conseguidos, se siguen reconociendo déficits de institucionalización y de estudios por realizar; éste es un tema que está, seguramente como otros tantos, sujeto todavía de profundas revisiones que reta a nuevos descubrimientos. El caso latinoamericano (Figueroa 2002) es un campo sumamente fértil para explorar estas nuevas líneas de estudio.

\section{MODELOS IDEALES DE FUNCIÓN DIRECTIVA}

Un elemento particular para diferenciar los sistemas de profesionalización de la función directiva, está en la identificación de ciertos tipos o modelos configurados a partir de ciertas características, a pesar de la existencia de una multiplicidad de ellos que bien podrían ser únicos e incluso por cada país. De modo que es posible hablar de "Modelos Ideales de Función Directiva". Una breve distinción entre ellos es la siguiente (Jimenez Ascencio 2006).

\section{MODELO CORPORATIVO O CERRADO DE FUNCIÓN DIRECTIVA}

También denominado como modelo de carrera o burocrático, se caracteriza por ser un modelo de función directiva cerrado; esto es, que carece de ventanas abiertas al exterior. Lo distintivo es que la función directiva se extrae de la propia organización; es decir, son los propios funcionarios quienes, tras un largo período de desempeño de funciones estrictamente funcionariales, pasan a desempeñar funciones directivas y ocupan los 
puestos directivos en el sector público como una especie de coronación de la función directiva.

De manera que, principalmente, se caracteriza porque el servidor público es reclutado y seleccionado en pie de rama para la realización de una carrera específica en el servicio público, en la que las promociones y remuneraciones están reguladas estatutariamente. Hay una serie de requisitos para el ingreso ligados preponderantemente a méritos académicos. Estos sistemas son altamente jerárquicos con respecto al desarrollo de la carrera y sus niveles. El servidor público que forma parte del sistema de carrera, contará con una posición de carácter permanente, una vez que haya demostrado o aprobado el período de prueba. Las condiciones de trabajo, la remuneración y las pensiones y regulaciones relacionadas están decididas por autoridades y negociadas con los sindicatos. Cabe señalar que las competencias directivas no están definidas formalmente y la selección sigue criterios de carrera y cooptación interna. Los ejemplos de países próximos a este modelo, lo son Francia e Inglaterra (hasta antes de la reforma Next Steps).

Según Jiménez Ascencio (2006: 39-40), los mayores inconvenientes que presenta este sistema de dirección pública radican en el dato que el nombramiento como directivo público de un funcionario es una especie de continuidad de la carrera administrativa (lo que puede implicar una ocupación de los niveles directivos por lógicas funcionariales y directivas) y que, por lo común, se otorga su desempeño con carácter vitalicio, circunstancia que, dada la garantía de permanencia, impide evaluar hasta qué punto el directivo público desempeña bien sus cometidos. Su mayor ventaja tal vez estribe en el hecho de que los directivos públicos son captados dentro de la propia organización, lo que supone que conozcan bien el contexto, el entorno y sus propios límites.

\section{MODELO DE POLITIZACIÓN U OCUPACIÓN POR LA POLÍTICA DE LOS PUESTOS DIRECTIVOS}

Éste es un sistema abierto, que parte del principio de que los servidores públicos no son empleados para una carrera específica sino para un puesto particular. Los puestos directivos en el sector público pueden ser ocupados por cualquier persona independientemente de sus capacidades y de su procedencia. Es un modelo que arranca desde los parámetros típicos del spoil system y que implicaba en su acepción más primaria que todos los empleos de la administración se debían proveer por criterios de confianza política en cuanto a su desempeño no ofrecía especiales dificultades. De modo que la designación se realiza con discrecionalidad absoluta. Este modelo de politización de la función directiva se caracteriza porque el elemento determinante en la provisión de puestos es la confianza política 
hasta el punto que el resto de criterios (profesionalidad, capacidad o mérito) resultan puramente adjetivos.

Éste es un sistema vigente todavía en muchos países, al menos en lo que corresponde a la ocupación de los niveles superiores de la administración pública o próximos a la política. Aunque algunos países anglosajones lo han desterrado por completo. Los ejemplos, son desde casi todos los países latinoamericanos, asiáticos, africanos, y el caso espańol, mientras no se implemente del todo la nueva normatividad publicada en 2007.

En cuanto a ventajas y desventajas, el propio Jiménez Ascencio (2006: 44) señala que siempre se ha indicado que la gran ventaja es la flexibilidad que presenta el reclutamiento y cese como consecuencia de la enorme discrecionalidad (absoluta libertad) que tiene el órgano que designa y cesa. En relación a las desventajas se dan en función del propio proceso, esto es, los directivos públicos, al ser reclutados con base exclusivamente en la confianza política y sin ningún tipo de exigencias (en algunos casos ni siquiera académicas) de mérito ni de capacidad $y$, por tanto, son personas imbuidas de un fuerte "amateurismo", con un desconocimiento profundo del sector público en el que deben de actuar. Asimismo, la dependencia del mandato del directivo público del propio ciclo de la política provoca que el capital directivo se esté constantemente renovado y se pierda una fuente de experiencia y conocimiento que una organización no puede prescindir.

\section{MODELO GERENCIAL O PROFESIONAL DE DIRECCIÓN PÚbLICA}

Este modelo surge como reacción a los otros dos modelos, y es en el mundo anglosajón en el que se arraigan los elementos básicos de este modelo de dirección pública, cuya característica fundamental no es otra que la identificación de una función directiva en el sector público dotada de una serie de rasgos profesionales que la singularizan frente a la actividad estrictamente política y frente a la tradicional tarea de la burocracia profesional (el servicio civil). El rasgo fundamental de este modelo gerencial es, el descubrimiento de que hay una función directiva específica y que el correcto desempeño de esas funciones directivas requiere de fuertes dosis de profesionalización. Las experiencias gerenciales de determinados países anglosajones como Estados Unidos, Reino Unido y Nueva Zelanda dieron impulso a este modelo gerencial que más tarde se reconstituyó a partir de la Nueva Gestión Pública (Jiménez Ascencio 2006: 46).

Este es el modelo resultante del desarrollo de ideas y valores de eficacia y eficiencia en el sector público. Tiene cierta influencia del sector privado y exige la caracterización de puestos directivos. Como ya se señaló, se parte del reconocimiento que la función directiva es una actividad de naturaleza profesional, que por tanto se requiere de una serie de conocimientos $y$ 
habilidades vinculadas con las tareas directivas (que son diferentes desde el punto de vista cuantitativo y cualitativo de los conocimientos y habilidades exigidos para el desempeño funcionarial). Por lo que se estaría hablando en este rubro más de competencias sobre cualquier otro precepto, de forma que existe un procedimiento público de selección o designación basado en la demostración de la posesión de competencias. Por otro lado, los directivos públicos una vez seleccionados, disponen de poderes propios o delegados para dirigir la organización (personal, organización, presupuestos). Se intenta dejar que los gestores gestionen, en el marco de planes o contratos programa definidos por el gobierno (Villoria y Del Pino 2009: 502). Todo ello, en un marco de responsabilidades y de rendición de cuentas específico, con un sistema de premios y castigos propio, con una cierta temporalidad o plazo definido, pero sin que el cese se realice de manera discrecional o con interés político.

Según Manuel Villoria y Eloisa del Pino (2009: 502-503) tras analizar los tres modelos parece que el único que responde a los criterios de una función directiva profesional es el modelo gerencial. El primero es profesional pero no es directivo. El segundo puede ser directivo pero no es profesional y sólo el tercero permite articular dirección con profesionalidad.

\section{COMPONENTES PARA LA INSTAURACIÓN DE UN SISTEMA DE PROFESIONALIZACIÓN PARA LA FUNCIÓN DIRECTIVA}

El establecimiento de un sistema de profesionalización para la función directiva plantea, necesariamente, la construcción de una serie de componentes para su diseño e implementación. Desde nuestra perspectiva, tales componentes tienen que girar en torno a los siguientes puntos.

\section{Contar con El apoyo deSDE El Más ALTO NIVEL TANTO DE AUTORIDADES EJECUTIVAS COMO LEGISLATIVAS}

Este componente tiene que ver principalmente con un elemento fundamental para el debido éxito de este tipo de iniciativas con la "voluntad política” requerida. La experiencia comparada demuestra que las iniciativas de profesionalizar la función directiva han requerido del apoyo desde el más alto nivel, y no de manera casual, la dirección de este proceso está cercana a la primera magistratura, tales sistemas son administrados en su mayoría por oficinas o dependencias de personal, directamente vinculados con el Presidente o Primer Ministro del gobierno. Por su parte, los poderes legislativos (en los que están representados los partidos políticos) participan en la elaboración de leyes y normas ligadas a su funcionamiento, y sin duda con su intervención avalan su proceder y funcionamiento. Desde ahora, afirmaríamos que sin este soporte difícilmente una función directiva profesional prosperaría. Por lo que el apoyo de estas instancias 
es básico, tanto por la legitimidad que aportan, como por el impulso e importancia que se le tendría que dar a esta figura para el fortalecimiento de la administración pública y el sistema político en su conjunto.

El escenario antes descrito, trae consigo dos asuntos de carácter relevante: en primer lugar, que el tema de la función directiva esté en la agenda política-administrativa y esperaríamos también en la agenda de los partidos, y que una vez que se enlacen esfuerzos tanto de carácter legislativo como administrativo, en su conjunto den lugar a la implementación de una política pública en la materia, reconocida y ligada a demás esfuerzos colectivos por mejorar las condiciones de los servidores públicos en general.

\section{CONSTRUCCIÓN DE ARREglos INSTITUCIONALES ENTRE POLÍticos Y DIRECTIVOS}

En palabras de Carles Ramió (2006):

...el elemento más problemático de la regulación del espacio directivo en la Administración pública es el encaje de la política y su relación con la dirección profesional. Éste es un tema clásico de estudio de la Ciencia Política, de la Ciencia de la Administración y de la Teoría de la Administración. Es sin duda la dirección, la parte más estratégica de las organizaciones públicas ya que tiene una ineludible y necesaria naturaleza política ya que en esta circunstancia pivotea la legitimidad democrática y el engarce del sistema administrativo con el sistema político. También es cierto que en un punto más o menos estratégico aparece la dirección profesional y que la vinculación de ésta con la dirección política tiene sus problemas de lenguaje o prioridades. Por otro lado, es evidente la ingenuidad de la división wilsoniana en la que se podía diferenciar claramente en las administraciones públicas la dimensión política de la dimensión profesional. Más bien al contrario, en nuestra opinión, ambas dimensiones están en la gestión pública real muy interrelacionadas y mezcladas. Pero una cosa es reconocer esta interrelación y otra muy distinta es considerar este espacio políticoprofesional como un confuso magma en el que todo está mezclado y en el que no caben reglas ni regulaciones. Esta interpretación suele ser interesada y tiende a generar de facto una excesiva politización de los aparatos administrativos. En contra, nuestra posición considera que, a pesar de la interrelación entre la dimensión política y la dimensión administrativa, es necesario regular el espacio de cada componente no tanto para separar, finalidad carente de sentido, sino de clarificar unas posiciones y reglas del juego que pueden favorecer el rendimiento institucional de las administraciones públicas.

En efecto, un asunto clave en la instrumentación de una función pública 
profesional, será la de establecer con claridad las reglas del juego tanto para los políticos como para los directivos. Precisamente, como lo apunta Ramió (2006), no en el ánimo de separar, sino sobre de todo de clarificar espacios y posiciones en el interés de conjugar esfuerzos para la elaboración de políticas públicas, entre las cosas más importantes. Este componente es clave, y está vinculado principalmente con la identificación de roles y niveles de responsabilidad que le corresponde realizar tanto a los políticos como a los directivos.

La definición de tales posiciones y responsabilidades o espacio necesario que debe tener cada uno de estos actores, requerirán como soporte una serie de normas y reglas escritas, pero también vale considerar a las no escritas, relacionadas más con la construcción de acuerdos, códigos y un sistema de valores para ambos actores que en su conjunto, más allá de explicar límites de actuación, también denoten una comunicación clara y precisa de lo que le corresponde hacer a cada uno de ellos.

No está de más señalar que en la identificación de posiciones y la construcción de espacios propios, pareciera ser que -al menos en países de Latinoamérica- se tiene una mayor claridad de lo que es y representa el rol del político, más no así, para el caso del directivo y también agregaríamos al servidor público en general. En lo que corresponde a los directivos, la imagen es difusa, poco reconocida. En gran parte, se considera que esto se debe a la carencia de un sistema profesional que los respalde, que hace que a los directivos, por ser designados en su mayoría por los políticos en calidad de sus jefes, se les identifique también como políticos. Caso contrario, de haberse instrumentado medidas de profesionalización que hubieran coadyuvado a contar con un función directiva profesional institucionalizada, esto hubiera derivado en situación más de primus inter pares entre los políticos y los directivos, en lugar de una relación de subordinación de los segundos en relación a los primeros.

De manera que es importante advertir, porque sin duda éste es uno de los componentes más complejos de la implementación de esta figura, lo que señala Franciso Longo (2006: 65-66) en cuanto a pesar de tener una primera gran aproximación del qué y para qué de los directivos públicos, es importante señalar, que sus contornos no han alcanzado todavía, ni en su aplicación práctica ni en la elaboración teórica de los académicos, un grado de precisión que facilite una delimitación conceptual de la figura. Así las cosas, el esfuerzo por medir su grado de desarrollo e institucionalización real se torna, hoy por hoy, en un propósito lleno de dificultades. Estas dificultades se acrecientan si pensamos en la complejidad de los entornos institucionales en los que los directivos públicos están llamados a arriesgarse y a ser analizados, o lo que viene a ser lo mismo, la diversidad de factores 
que pueden contribuir a su desarrollo y consolidación. Esto, por supuesto, hace más atractivo su estudio y análisis.

Un tema relevante en el estudio de los arreglos institucionales entre políticos y directivos radica, por una parte, en el análisis de la evolución de los directivos y su lugar cada vez más destacado en las administraciones públicas, y por el otro, en las relaciones que se establecen entre ambos actores. De modo que se observa a una función directiva que como colectivo de personas, gana cada vez mayor autonomía con relación a la clase política, basándonos en el enfoque promovido por Goodsell (1994), Rohr (I 986) y Friedrich (I940). De igual modo, esto tiene que ver con las relaciones que se establecen entre directivos-políticos/políticos-directivos a través del análisis de diversos modelos teóricos de relación entre ambos actores. Para ello, la base teórica principal está en los trabajos de Joel Aberbach, Robert Putman y Bert Rockman (I98 I), Guy Peters (1987), y de Poul Erik Mouritzen y James Svara (2002). Por cierto, literatura escasa en su desarrollo y aplicación para países latinoamericanos.

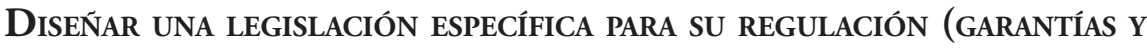 DERECHOS Y DEBERES PROFESIONALES)}

Las legislaciones específicas lo que pretenden precisamente es refrendar el tratamiento especial que requiere una figura como lo es la función directiva profesional. Legislación que estipule una serie de derechos y deberes para los directivos, con los que cuentan los diferentes tipos de personal que forman parte de la burocracia. Legislaciones que, como ya se dijo en el primer capítulo, bien pueden ser distintas a las que regulan al personal del servicio civil u otro tipo de personal como pudiera ser el operativo.

Para el caso de Latinoamérica, bien se pudieran establecer dos alternativas, la primera de ellas es contar con una legislación y normas propias para la función directiva, o en el marco de sus legislaciones marcar la distinción para la función directiva. Por ejemplo, tal como está previsto en el Estatuto de la Función Pública de España publicado en el 2007.

En el mismo sentido, el hecho de contar con una legislación particular está asociado con el hecho de prever la existencia de un aparato u organización responsable de su administración, con características de funciones especializadas para llevar a cabo las tareas por realizar. Llámese una oficina particular que tenga la responsabilidad la gestión de la función directiva profesional.

Ahora bien, todo esto en cuanto a lo correspondería a la parte formal o normativa, pero también cabe aclarar que para impulsar un función directiva profesional no se necesitaría una legislación específica, están los 
casos que se mencionaron en la introducción de esta investigación como lo son Alemania, Dinamarca, Francia, que si bien no hay reglas específicas, si hay una atención sólida, además de reconocer la importancia del directivo y de la posición que juega en la elaboración de políticas públicas y como agente de cambio.

Lo que es una realidad es con legislaciones o sin legislaciones, la importancia de la función directiva profesional, por si misma, obliga en los tiempos actuales a su atención, revisión y estudio sino es que a su necesario desarrollo.

\section{ESTABLECER EL ÁMBITO DE APLICACIÓN PARA EL DESARROLLO DE LA FUNCIÓN DIRECTIVA}

Este punto se refiere a cuál será el ámbito de aplicación para la función directiva. Esto va desde considerar, por un lado a los diferentes órdenes de gobierno, a identificaral interior de cada uno de ellos, si lainstitucionalización de la función directiva profesional será para sólo la administración pública centralizada o también considerara a la administración pública paraestatal o, como ha acontecido en otros países, que no sólo se ha circunscrito a los ministerios y departamentos sino también a nivel de agencias.

La definición del ámbito de aplicación estará en función de los intereses en boga y del nivel de profesionalización alcanzado por las propias administraciones públicas. Desde nuestro punto de vista, la implementación de una función directiva profesional para el caso de Latinoamérica, tendría que ser transversal tanto a la administración pública centralizada como paraestatal. O bien, se pudiera pensar que su construcción fuera gradual, siendo la centralizada un primer escenario de desarrollo.

De igual modo, el ámbito aplicación por delimitar también nos da indicios del nivel de centralización o descentralización que podría aplicarse en la implementación de esta figura. La experiencia comparada nos indica que a mayor amplitud en la selección de organizaciones suele darse una mayor descentralización. En este punto, también habrá que considerar escenarios en el que sea un órgano de la administración el responsable de su manejo, un órgano externo, o que cada organización establezca su propio sistema de gestión de recursos humanos bajo directrices de carácter general. En esto también hay un mundo de posibilidades.

\section{Delimitar el Número de puestos a SER SUjetos para la función DIRECTIVA}

Tal como ha acontecido en otros países, que han construido su función directiva delimitando ciertos puestos para ella, o ya sea que su diseño se 
hizo a partir de haber tomado niveles tanto de cargos directivos y políticos para su conformación, en efecto el interés consiste en identificar una serie de niveles o puestos de una estructura próximos a perfiles directivos que serían sujetos de profesionalización.

Por poner como ejemplo el caso de México, la propuesta para la función directiva profesional consistiría en seleccionar dos puestos del servicio profesional de carrera, en este caso, el de Director General y el de Director General Adjunto, y un puesto político correspondiente al de Titular de Unidad. Con esos tres puestos, se considera que se podría iniciar un sistema de profesionalización para directivos públicos, tomando en cuenta que el escalafón a nivel vertical no es muy amplio. Pero en contraparte, por cada puesto seleccionado para la función directiva profesional, se apueste hacia la horizontalidad, con incrementos salariales diferenciados, todo a partir de una banda amplia de niveles.

\section{Proponer el modelo de Profesionalización}

El modelo de profesionalización para la función directiva, parte de la distinción de ser un sistema de empleo o un sistema de carrera o un sistema mixto. Esta definición es esencial, ya que a partir de ahí, se tienen que diseñar y desplegar procesos tan relevantes como el tipo de concursos (por ejemplo, si serán abiertos o cerrados o de los dos tipos), la carrera profesional (propio más de un servicio cerrado), el modelo de evaluación del desempeño (si es por competencias, más próximos a puestos o sistema de empleo), los contratos de desempeño, el desempeño ligado a retribuciones económicas vía resultados, el tipo de capacitación, el uso de tecnologías de la información y comunicación, entre los más sobresalientes.

\section{Crear los entornos institucionales Indispensables}

La construcción de una función directiva profesional y las expectativas en torno a contar con directivos con niveles de actuación, diferentes con lo que se pudiera identificar con los estilos directivos tradicionales, no es una tarea fácil. Sobre todo porque esta labor no sólo se circunscribe al fortalecimiento de la función directiva como tal, llámese a través de normas, herramientas de gestión de recursos humanos, así como la propia construcción de una cultura directiva. El reto va más allá, y tiene que ver con la alineación y desarrollo de condiciones externas que hagan fértil y productiva la función directiva.

Por ejemplo, no se le puede pedir a un directivo que se conduzca sobre la base de un esquema por resultados, cuando su entorno presupuestal no tiene tal orientación. De igual manera, no se le puede pedir a un directivo que su actuación esté ligada hacia la innovación, si de por medio 
están presentes los controles administrativos tradicionales, que en lugar de incentivar están más próximos a inhibir. En esta misma línea de los ejemplos, si al directivo no se le construye un sistema de estímulos e incentivos difícilmente también se le podrá exigir mayores resultados de los que podría adoptar. Todo ello, aunado a una reivindicación tanto de su posición ante los políticos como ante la sociedad.

Este componente es, seguramente, el más complicado de todos los que se han mencionado, ya que como se puede observar el nivel de participación de otros temas y actores, es mucho más elevado, complejo y diverso. Pero sólo así, teniendo como base una idea común y una construcción colectiva es como se podrían conseguir bases sólidas para hacer posible la existencia de una función directiva profesional en toda la extensión de la palabra.

\section{IMPULSAR UN PROCESO DE SOCIALIZACIÓN DE LA FUNCIÓN DIRECTIVA}

La socialización es un elemento también fundamental, tomando en cuenta que se percibe una falta de comprensión y conocimiento de lo que es y representa la profesionalización de los servidores públicos, y no se diga para el caso que nos compete: la función pública directiva. Si partimos que para ciertos sectores de la clase política, países de Latinoamérica, en el que hay un abierto desinterés y desconocimiento sobre lo es y representa el tema de la profesionalización en esa esfera, está claro que no podemos esperar más con respecto a la ciudadanía. En efecto, si no se sabe con certeza que representa tanto un servicio profesional de carrera y una función directiva profesional, y si a eso se agrega el desdén y la predisposición negativa existente por parte de la ciudadanía, pues simplemente será difícil reconocer su utilidad.

En ese sentido, es menester que su utilidad en un sistema democrático se conozcan y se difunda, a través de toda un "red de aliados" en los que no sólo estén presenten los propios gobiernos y administraciones públicas, sino también las universidades, los colegios de profesionistas, los partidos políticos, las sindicados, las organizaciones de la sociedad civil, los medios de comunicación, entre otras instancias.

Como se puede observar, una vez mencionados todos estos componentes, hay muchos retos por llevar a cabo, que al mismo tiempo dan lugar a por un lado, a múltiples preguntas y por el otro, a líneas de investigación que desde nuestro parecer, resulta conveniente abordar desde ahora, algunas de ellas, con mayor nivel de dificultad que otras, que incluso llevarían más tiempo, y que darían material para el desarrollo de estudios individualizados. Sin embargo, se considera que se está en la coyuntura adecuada de poder avanzar en estos momentos, para crear las bases de una función pública directiva profesional en los países de la región latinoamericana. 
La función directiva profesional, es uno de los principales temas de la reforma y modernización de las administraciones públicas. El simple hecho de mencionar el enunciado resulta ser sumamente atractivo; evidentemente que la parte más retadora consistirá en cómo se puede hacer factible el impulso de un esquema de esta naturaleza entre todo el engranaje institucional del país. Este trabajo de investigación, pretende precisamente dar algunas orientaciones a fin de construir los elementos suficientes para avanzar en esta asignatura.

\section{CONCLUSIONES}

Como se puede observar, la construcción de componentes para el establecimiento de un servicio profesional para la función directiva no se presenta como una tarea fácil y sencilla. No sólo en esta empresa se tienen que combinar aspectos de carácter normativo y técnico, sino también elementos de carácter político y cultural.

Aunado a todo esto, vale la pena hacer establecer una serie de preguntas por contestar para la construcción de un sistema de profesionalización para directivos públicos en Latinoamérica vinculadas a su diseño institucional, y tendrían que ser las siguientes:

- ¿Qué tipo de administración pública se quiere y a partir de ello que tipo de directivos públicos se necesita definir?

- ¿Qué se requiere de los directivos públicos? ¿Qué objetivos deben de conseguir?

- ¿Qué tanto el sistema político de los países de Latinoamérica es proclive a producir directivos públicos con las capacidades necesarias? Pero sobre todo, ¿es propicio el sistema para retener el talento necesario y desarrollarlo?

- ¿Están, hoy día, las personas responsables de la política como de la administración compartiendo la misma visión y los mismos valores para impulsar una propuesta de profesionalización de directivos públicos?

- ¿Cuál es la percepción que tienen nuestros políticos de los directivos públicos?

- ¿Les interesa realmente a nuestros políticos electos y designados este asunto de la profesionalización? ¿En ellos se tiene un verdadero apoyo y aliado?

- ¿Se han construido los suficientes argumentos y evidencias para 
convencernos y convencer a los demás de la importancia de la profesionalización de nuestros servidores públicos?

- ¿Está presente en la cultura política administrativa del país el papel y la importancia de los directivos públicos?

- ¿Cuáles son los obstáculos y resistencias por abatir para poder establecer una carrera de directivos públicos en Latinoamérica?

- ¿En qué aspectos se verían afectadas las relaciones entre políticos y servidores públicos con la inserción de una carrera de altos directivos públicos?

Por otro lado, desde la perspectiva de la gestión de recursos humanos para directivos públicos, irremediablemente nos obliga a explorar las siguientes líneas de investigación:

- Diseño de procesos de selección para directivos públicos.

- Elaboración de procesos de formación de directivos públicos.

- Revisión de sistemas de evaluación del desempeño para la función directiva.

- Construcción de una familia de capacidades genéricas y por área.

- Identificación y/o creación de herramientas para medir capacidades directivas.

- Desarrollo de habilidades de personales y emocionales para los directivos públicos.

- Definición de áreas encargadas de la selección de directivos públicos, así como posibles centros de formación y análisis de perfiles de personal responsable de la gestión de la función directiva.

- Revisión de tabuladores alineados con la evaluación del desempeño.

- Análisis de procesos presupuestarios para orientarlos a resultados.

- Revisión de sistemas de competencias para directivos públicos.

- Registro y análisis de los que están haciendo otros países en esta materia.

- Revisión de tecnologías de la información para la gestión de la función directiva. 
El sistema de profesionalización para altos directivos públicos requiere al igual que lo se ha venido construyendo en materia del servicio civil, de un tiempo importante y de elementos que le den forma, así como de lecciones aprendidas, para que pueda ser de interés en el medio en el que se quiere implantar, y de elementos adicionales como lo son el análisis de condiciones normativas y de operación, dinámicas internas, trabajo in situ, la adecuada preparación de esos directivos pero también de los políticos, entre lo más relevante. Adicionalmente, requiere de un amplio apoyo por parte del titular de la administración pública, que incluye un desarrollo de negociaciones con diferentes actores, así como la construcción de redes que hagan sostenible el proyecto. Y que tenga como horizontes no sólo a la administración pública sino también a los otros poderes públicos, así como a otros órdenes de gobierno. 


\section{REFERENCIAS}

Aberbach, J., Putman R. y Rockman B. (198I). Bureaucrats and Politicians in Western Democracies. Cambridge: Harvard University Press.

Banco Interamericano de Desarrollo (BID). (2003). Red de Gestión y Transparencia de la Política Pública y el Servicio Civil: Temas para el Diálogo. Wahington: BID.

Banco Mundial (BM). (2003). Making Services Work for Poor People 2004. Nueva York: The World Bank Group and Oxford University Press.

Brosnahan, J. (2000). Public Sector Reform Requires Leadership. Government of the Future. Paris: OCDE.

Cardona Peretó, F. (2007). Tendencias en la Gestión de la Función Pública. Países Unión Europea y OCDE. Revista Servicio Profesional de Carrera, 7.

Catalá Polo, R. (2005). Directivos Públicos. Presupuesto y Gasto Público, 4I, 2II-225.

Centro Latinoamericano de Administración para el Desarrollo (CLAD). (2003). Carta Iberoamericana de la Función Pública. Caracas: CLAD.

Dussauge-Laguna, M. (2008). Categorías y Características de los Servidores Públicos en un Gobierno Profesionalizado. Revista Servicio Profesional de Carrera, 9.

Ezra, N. (1984). Bureaucrats and Policy Making. Nueva York: Holmes and Meyer.

Fayol, H. (196I). Administración Industrial y General. Buenos Aires: El Ateneo.

Figueroa, R. (2002). Regímenes de Directivos Públicos en América Latina: Estado de Arte, Análisis y Conclusiones. Washington: Banco Interamericano de Desarrollo.

Gardner, J. (1990). On Leadership. Nueva York: The Free Press.

Goodnow, F. J. (I 900). Politics and Administration: A Study in Government. Londres: MacMillan.

Goodsell, C. (1994). The Case for Bureaucracy: A Public Administration Polemic. Nueva Jersey: Chatham House. 
Gulick, L. (1987). Notes of the Theory of Organization. En Shafritz, J. M. y Ott J. S. (Ed.), Classics of Organization Theory. Chicago: Dorsey Press.

Heady, F. (1996). Public Administration. A Comparative Perspective. Nueva York: Marcel Dekker.

Heifetz, R. (1994). Leadership without Easy Answers. Londres: Cambridge University Press.

Holden, P., Pederson C.A. y Germone G. (I968). Top Management. Nueva York: McGraw Hill.

Hopf, H. A. (I96I). Scholarly Practitioner and Pioneer in Management. The Journal of the Academy of Management. 4 (3), 23 5-244.

Jacoby, H. (1973). The Bureaucratization of the World. Berkeley: University of California Press.

Jiménez Ascencio, R. (2006). Directivos Públicos. Bilbao: Instituto Vasco de Administración Pública.

Keraudren, Ph. y Van Merlo H. (I998). Theories of Public Management Reform and their Practical Implications. En Verheijen, T. \& Combes D. (Comps.), Innovations in Public Managment. Perspectives from East and West Europe. Cheltenham: Edward Elgar.

Kliksberg, B. (1983). Universidad, Formación de Administradores y Sector Público en América Latina. México: Fondo de Cultura Económical INAP-CLAD.

Kotter, J. (1983). Lo que Hacen Realmente los Buenos Directores Generales. Harvard-Deusto Business Review, I 5 (3), 54-68.

LaPalombara, J. (1963). Bureaucracy and Political Development. Princeton: Princeton University Press.

Laufer, R. y Burlaud A. (1988). Dirección Pública: Gestión y Legitimidad. Madrid: Ministerio de las Administraciones Públicas.

Likert, R. (196I). New Patterns of Management. Nueva York: McGraw Hill.

Lipsky, M. (1980). Street-Level Bureaucracy. Dilemmas of the Individual in Public Services. Nueva York: Russell Sage.

Longo, F. (2002). Políticos, Directivos y Sindicatos como Actores de la Gestión de Recursos Humanos en las Administraciones Públicas. En 
Longo F. \& Zafra M. (Coords.), Pensar en lo Público. Madrid: UIMESADE.

- (2003). La Reforma del Empleo Público en las Democracias Avanzadas: Mérito con Flexibilidad. En Echebarría, K. (Ed.), Red de Gestión y Transparencia de la Política Pública: Temas para el Diálogo. Washington: Banco Interamericano de Desarrollo.

. (2004). Mérito y Flexibilidad. La Gestión de las Personas en las Organizaciones del Sector Público. Barcelona: Paidós.

. (2006). Oferta y Demanda de Gerentes Públicos. Un Marco de Análisis de la Institucionalización de la Dirección Pública Profesional. Revista Reforma y Democracia. Revista del CLAD, 35.

Matheson, A., Weber B., Manning N. y Arnould E. (2007). Study on the Political Involvement in Senior Staffing and on the Delineation of Responsabilities between Ministers and Senior Civil Servants. París: OCDE.

Merrill, H. y Marting E. (Eds.). (1958). Developing Executive Skills: New Patterns for Management Growth. Industrial and Labor Relations Review. Nueva York: American Management Association.

Ministerio de las Administraciones Públicas. (2005). Informe de la Comisión del Estatuto Básico del Empleado Público. Madrid: Ministerio de las Administraciones Públicas.

. (2007). Estatuto Básico del Empleado Público. Madrid: Ministerio de las Administraciones Públicas.

Ministerio Secretaría General de la Presidencia. (200I). Estatuto de la Dirección Pública. Santiago: Ministerio Secretaría General de la Presidencia.

Mintzberg, H. (1983). La Naturaleza del Trabajo Directivo. Barcelona: Ariel.

- (1996). Managing Government, Government Management. Harvard Business Review, 74 (3), 75-83.

. (2000). Developing Leaders? Developing Countries? Oxford Leadership Journal, I (2), I-IO.

. (2005). Directivos, no MBAs. Una Visión Crítica de la Dirección de Empresas y la Formación Empresarial. Barcelona: Deusto. 
Morstein, F. (1957). The Administrative State. Chicago: Chicago University Press.

Mouritzen, P. E. y Svara, J. (2002). Leadership at the Apex Politicians and administrators in western local governments. Pittsburgh: University of Pittsburgh Press.

Office of Personnel Management. (200I). Guide to the Senior Executive. Washington: Office of Personnel Management.

Organización para la Cooperación y el Desarrollo Económico (OCDE). (1995). Top Management Service in Central Government: Introducing a System for the Higher Civil Service in Central and Eastern European Countries. Paris: OCDE.

- (1997). La Transformación de la Gestión Pública. Las Reformas de la OCDE. Madrid: Ministerio de las Administraciones Públicas. Autor.

. (1998). Managing the Senior Public Service a Survey of OECD Countries. Paris: OCDE.

. (I999). The State of the Higher Civil Service After Reform; Britain, Canada and the United States. Public Management Service. Paris: OCDE.

. (2000). Government of the Future. Madrid: Ministerio de las Administraciones Públicas. Paris: OCDE.

. (2003). Managing Senior Management: Senior Civil Service Reform in OECD Members Countries. Paris: OCDE..

. (2008). The Senior Civil Service in National Governments of OECD Countries. Paris: OCDE. . (2008). The State of Public Service. Paris: OCDE.

Peters, G. (1987). Politicians and Bureaucrats in the Politics of Policy Making. En Lane, J. E. (Ed.), Bureaucracy and Public Choice. Londres: SAGE.

. (1995). The Politics of Bureaucracy. A Comparative Perspective Nueva York: Longman.

. (2003). El Nuevo Institucionalismo. Teoría Institucional en Ciencia Politica. Barcelona: Gedisa.

Price Waterhouse. (1988). Straight from the CEO. Nueva York: Simon \& 
Schuster.

Ramió, C. (2006). Política y Gestión: La Regulación del Directivo Público en España Ponencia presentada al II Congrès Català de Gestió Pública, julio, Buenos Aires. Barcelona.

Red Mexicana por la Profesionalización del Servicio Público. (2004). Carta Iberoamericana de la Función Pública. Revista Servicio Profesional de Carrera, 2.

Riggs, F. W. (1970). Frontiers of Development Administrations. Durham: Duke University Press.

Rohr, J. (1986). To Run a Constitution: The Legitimacy of the. Administrative State. Lawrence: University Press of Kansas.

Rowat, D. (1988). Public Administrations in Developed Democracies. Nueva York: Marcel Dekker.

Sayles, L. R. (1964). Managerial Behavior: Administration in Complex Organizations. Nueva York: McGraw Hill.

State Services Commission. (200I). A Cross-Jurisdictional Scan of Practices in Señor Public Services: Implications for New Zealand. Wellington: State Services Commission.

Stewart, R. (I 988). Managers and their Jobs.. Londres: McMillan.

Villoria, M. y Del Pino, E. (2009). Dirección y Gestión de Recursos Humanos en las Administraciones. Madrid: Tecnos.

Weber, M. (1979). Economía y Sociedad. México: Fondo de Cultura Económica.

Wilson, W. (i 887). Study of the Administration Political. Political Science Quarterly, 2(2), 197-222.

Recibido: I2-O3-20I2

Aceptación de la versión final: 29-06-20 I 2 